\title{
Medicinal clays improve the endurance of loaded inspiratory muscles in COPD: a randomized clinical trial of nonpharmacological treatment
}

This article was published in the following Dove Press journal:

International Journal of COPD

23 October 2015

Number of times this article has been viewed

Simonetta Baldi,' Gian

Domenico Pinna, ${ }^{2}$ Claudio

Bruschi,' Fabrizio Caldara, ${ }^{3}$

Roberto Maestri, ${ }^{2}$ Elena

Dacosto,' Antonella Rezzani,'

Ermanno Popovich,' Ezio

Bellinzona,' Paola Crotti,' Silvia

Montemartini,' Claudio Fracchia'

'Department of Pneumology,

${ }^{2}$ Department of Biomedical

Engineering, Scientific Institute

of Montescano, Salvatore Maugeri

Foundation, Istituto Di Ricovero

e Cura a Carattere Scientifico,

Montescano (Pavia), ${ }^{3}$ Center of

Thermal Studies Pietro d'Abano,

AbanoTerme, Padua, Italy

\section{Video abstract}

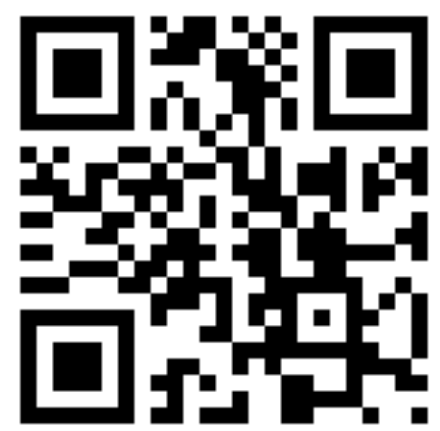

Point your SmartPhone at the code above. If you have a QR code reader the video abstract will appear. Or use

http://youtu.be/abeuv6BwS3E

Correspondence: Simonetta Baldi UO di Riabilitazione Specialistica -

Pneumologia Riabilitativa, Istituto

Scientifico di Montescano, Fondazione

S Maugeri, IRCCS, Via Per Montescano

No 3I, 27040 Montescano, Pavia, Italy

Tel +390385247227

Fax +3903856 I386

Email sb664@le.ac.uk

simonetta.baldi@fsm.it
Background: Inspiratory resistive breathing (IRB) challenges affect respiratory muscle endurance in healthy individuals, which is considered to be an interleukin 6 (IL-6)-dependent mechanism. Whether nonpharmacological thermal therapies promote the endurance of loaded inspiratory muscles in chronic obstructive pulmonary disease (COPD) is unclear. The objectives of this study were to compare the effects of two thermal interventions on endurance time (ET) and plasma IL-6 concentration following an IRB challenge.

Methods: This study was a randomized, parallel-group, unblinded clinical trial in a single-center setting. Forty-two patients (aged 42-76 years) suffering from mild to severe COPD participated in this study. Both groups completed 12 sessions of the mud bath therapy (MBT) $(n=22)$ or leisure thermal activity (LTA) $(n=19)$ in a thermal spa center in Italy. Pre- and postintervention spirometry, maximum inspiratory pressure, and plasma mediators were obtained and ET and endurance oxygen expenditure $\left(\mathrm{VO}_{2 \text { Endur }}\right)$ were measured following IRB challenge at $40 \%$ of maximum inspiratory pressure.

Results: There was no difference in $\triangle \mathrm{IL}-6$ between the intervention groups. But, IRB challenge increased cytokine IL-6 plasma levels systematically. The effect size was small. A statistically significant treatment by IRB challenge effect existed in ET, which significantly increased in the MBT group $(P=0.003)$. In analysis of covariance treatment by IRB challenge analysis with $\mathrm{LnVO}_{2 \mathrm{Endur}}$ as the dependent variable, $\Delta \mathrm{IL}-6$ after intervention predicted $\mathrm{LnVO}_{2 \mathrm{Endur}}$ in the MBT group, but not in the LTA group. Adverse events occurred in two individuals in the MBT group, but they were mainly transient. One patient in the LTA group dropped out.

Conclusion: MBT model improves ET upon a moderate IRB challenge, indicating the occurrence of a training effect. The $\mathrm{LnVO}_{2 \mathrm{Endur}} / \mathrm{IIL}-6$ suggests a physiologic adaptive mechanism in respiratory muscles of COPD patients allocated to treatment. Both thermal interventions are safe.

Keywords: hydrotherapy, cytokine IL-6, inspiratory resistive breathing, balneotherapy, pulmonary rehabilitation

\section{Introduction}

Countries rich in mineral water use different options of hydrotherapy (HT) as a traditional medicine approach to cure chronic diseases.

Among the different effects of physical therapies with hypermineral thermal water, the antioxidant and anti-inflammatory effects of medicinal clays on skeletal muscles are acknowledged in several chronic diseases like osteoarthritis, ${ }^{1-4}$ but not in chronic obstructive pulmonary disease (COPD). In this condition, the clinical studies that have been undertaken to date have exclusively issued thermal water inhalations for treating upper and lower airway inflammation. ${ }^{5,6}$ No study has considered thermal mud pack 
application as a method to increase the muscle temperature, in order to test its ability to affect the performance of loaded respiratory muscles in COPD. ${ }^{7}$

Similar to a warm-up routine, thermal mud pack application might affect the performance of loaded inspiratory muscles via temperature-related mechanisms as well as nontemperature-related mechanisms, ie, via chemical and biochemical properties, which are achieved through the socalled maturation process of the thermal clay. ${ }^{8}$ Consequently, there could be the potential for medicinal clays to impact the cytokine systemic response elicited from breathing against inspiratory resistive loads.

Resistive breathing characterizes the course of many diseases of the respiratory system such as upper airway obstruction, bronchial asthma, and COPD exacerbations. ${ }^{9-11}$ In addition, strenuous breathing against an added high inspiratory resistance, ie, intensive resistive breathing in healthy subjects, experimentally mimics the condition encountered in respiratory diseases. ${ }^{12}$

Scientific evidence supports the role of inspiratory resistive breathing (IRB) as an immunologic challenge. ${ }^{12,13}$ Thus, IRB is here proposed as a test to challenge immunologic response of respiratory muscles in patients suffering from COPD while enduring at $\leq 50 \%$ of maximal inspiratory pressure.

The clinical trial is aimed to evaluate whether the constituents of thermal treatments in Abano-Montegrotto Terme SPA (the natural clay from Costa and Lispida thermal lakes and Hyper thermal [sulfur-rich mineral] water from Colli Euganei mineral-water field [BIOCE]) can affect the endurance of respiratory muscles challenged against an inspiratory resistive load. We conducted this clinical trial with a parallel-group design in patients suffering from COPD (Global Initiative for Chronic Obstructive Lung Disease [GOLD] stage I-III). We compared the mud (ie, medicinal clays) therapy (mud bath therapy [MBT]) model and the leisure thermal activity (LTA) model to test their efficacy in blunting the cytokine IL-6 plasma levels, circulating after a moderate IRB challenge. Further, we evaluated the effect of both thermal interventions on endurance time (ET), ie, the time to task failure. The cytokine IL- 6 change and time of endurance upon IRB challenge are taken as the endpoint variables.

Inspiratory time during IRB challenge $\left(T_{\text {I_IRB }}\right)$ and changes in endurance oxygen expenditure $\left(\mathrm{VO}_{2 \_ \text {Endur }}\right)$ upon the IRB challenge after thermal interventions were also explored to elucidate the homeostatic physiologic adaptations elicited in overloaded respiratory muscles by thermal interventions.

Although performed at a submaximal inspiratory pressure in a stable phase of the disease, we hypothesized that the acute IRB challenge may constrain the freely adopted pattern of breathing in patients with chronic expiratory airflow obstruction. And, it may elicit upregulation of transcription with ensuing increase in cytokine plasma levels.

If demonstrated, these effects would entail validating MBT model and LTA model as treatment options for individuals suffering from COPD and, in making passive warm-up routines a thermal and rehabilitative strategy to improve the endurance of inspiratory muscles.

\section{Materials and methods Design overview}

The study was a randomized clinical trial with a parallelgroup study design in which 42 patients suffering from COPD were allocated to either treatment or comparator group.

Before thermal interventions (Day 0), a complete pulmonary functional evaluation (spirometry, static lung volumes, CO-diffusing capacity, and arterial blood gases partial pressures) together with measurement of the study outcomes was carried out in a clinical respiratory function laboratory by qualified personnel. The tests were repeated after thermal interventions (Day 17) by the same staff.

On Day 0 and Day 17, all the patients were challenged against a submaximal linear inspiratory resistance during an IRB challenge. It was performed using a dedicated pressure threshold breathing device (Threshold IMT ${ }^{\circledR}$ Respironics).

We implemented the IRB challenge in COPD patients presenting with acute inspiratory loads to test endurance, ie, time to task failure. We measured respiratory oxygen consumption and acid lactic as markers of metabolic efficiency of respiratory muscles. Also, we assessed changes in reactive $\mathrm{C}$-protein together with changes in several plasma cytokines, namely IL-6, IL-1 $\beta$, and interleukin tumor necrosis factor alpha (TNF- $\alpha$ ), and adrenocorticotrophic hormone (ACTH), as markers of hypothalamic-pituitary-adrenal (HPA) axis stimulation.

On Day 1, all the enrolled patients moved to one of the selected thermal spa hotels in a major thermal site in Italy. Here they were allocated to receive treatment: MBT Group, or comparator: LTA Group. The groups were required to complete 12 sessions (Days 3-15) of either thermal treatment (MBT) model or comparator (LTA) model. The former consisted of the application of mud packs followed by a bath in thermal water provided by thermal-trained therapists. The latter consisted of unsupervised leisure thermal activities in the thermal pools.

According to the study protocol, the concealment of the patient's allocation ensured that investigator and outcome 
assessors were blind to group assignment, while participants and thermal therapists were not.

\section{Setting and participants}

We studied 42 patients with a clinical and functional diagnosis of COPD classified according to GOLD stages I-III. They were recruited into the study at Pulmonary Rehabilitation Unit of S Maugeri Foundation IRCCS (Montescano, Italy) from March 2010 to May 2013. It is a major pulmonary rehabilitation center, treating $>1,500$ cases annually.

Sites to deliver thermal treatment/comparator interventions were six selected spa hotels in AbanoTerme, Padua, Italy. A total of 12 thermal therapists participated in the study, two therapists per each thermal hotel. AbanoTerme is a major thermal center with a turnover of $>180,000$ patients annually.

Eligible patients were current or former smokers with smoking history of at least five pack-years, aged $>40$ years. According to GOLD guidelines, ${ }^{14}$ ratio of forced expiratory volume in 1 second to forced vital capacity $\left(\mathrm{FEV}_{1} /\right.$ $\mathrm{FVC}) \leq 70 \%$, and change of $\mathrm{FEV}_{1}$ after inhalation of Salbutamol $(400 \mu \mathrm{g})<12 \%$, and $<200 \mathrm{~mL}$ defines the presence of chronic airflow obstruction. The eligible individuals must not have received thermal care in the previous 2 years. Also, they must be able to accomplish the protocol requirements relevant to hotel accommodation for 2 weeks and confident about participating in leisure as well as thermal activities. Exclusion criteria were the presence of any specific contraindications to MBT, such as bronchial asthma, chronic respiratory failure due to severe pulmonary emphysema, cor pulmonale, and pulmonary arterial hypertension. They were excluded from the study if they presented with any malignancy, gastrointestinal disorders, severe endocrine disorders or recent (ie, within the last 4 weeks) surgery, respiratory tract infection, and abnormal fluid balance as manifested by the presence of edema or regular use of diuretics.

Participants kept taking all drug regimens prescribed within the previous 6 months, such as short-acting $\beta 2$-agonists (4/42) long-acting inhaled $\beta 2$-agonists (28/42), long-acting anticholinergic (28/42) inhaled corticosteroids therapy (fluticasone: 22/42, beclometasone: 4/42, and budesonide: 3/42). In addition, 8/42 kept taking formerly prescribed antihyperlipidemic, 34/42 antihypertensive, and $5 / 42$ antihyperglycemic medications. None of the patients was on either oral steroids or beta-blockers.

The medical ethics committee of the Scientific Institute of Montescano approved the study design. A written informed consent was obtained prior to the study.

\section{Randomization and interventions}

The study was a single-center controlled study. Simple (unrestricted) randomization was assured using a computer random number generator for generating the complete randomization sequences, which were concealed until assignment. The concealed allocation ensured that the investigator and outcome assessors were blind to thermal therapist/not supervised intervention allocation at the participating spa hotels.

Thermal MBT model consisted of a supervised intervention over 2 weeks. Once per day, a thermal-trained therapist applied the treatment by progressively packing the patient's skin with mud (ie, medicinal clay) packs at temperatures gradually increasing from $38^{\circ} \mathrm{C}$ to $42^{\circ} \mathrm{C}$. He covered the whole body with the exception of the head, cardiac area, and genital area. After 20 minutes, the patient took a shower to remove the mud pack. A thermal bath at $38^{\circ} \mathrm{C}$, lasting $8-15$ minutes, and 60 minutes bed rest, during which time the body was kept warm to favor the sweating reaction, completed the treatment. In addition, patients had free access to thermal swimming pools once or twice daily, to do unsupervised leisure activities in thermal swimming pools, each not exceeding 30 minutes.

Comparator LTA model consisted of a nonsupervised intervention over 2 weeks. Patients underwent 12 sessions of leisure activities (bathing, walking, swimming, etc) in thermal swimming pools twice daily, each not exceeding 30 minutes.

Overall, patients were empowered to record their oxygen saturation before and after each thermal activity session. They logged a self-reported card, listing their activities on a daily basis, number of sessions, and the relevant oxygen saturations $\left(\mathrm{SpO}_{2}\right)$.

\section{Pulmonary function tests and biomarkers in venous blood}

Lung function testing included spirometry $\left(\mathrm{FEV}_{1}\right.$ and $\left.\mathrm{FVC}\right)$ and thoracic gas volumes, which were measured using the spirometer and body box MasterScope ${ }^{\circledR}$ Body (VIASYS Healthcare GmbH, Wuerzburg, Germany). The single-breath CO-diffusing capacity was measured by a Baires System (Biomedin, Padua, Italy) using a gas mixture of $0.3 \% \mathrm{CO}$, 10\% helium, and balance air. Predicted equations utilized were those of Quanjer et al. ${ }^{15}$ An arterial blood sample was gently drawn from the brachial artery using a dedicated preheparinized blood syringe, while patients were seated and breathing room air. We measured the arterial negative logarithm of hydrogen ion concentration $(\mathrm{pH})$, arterial carbon dioxide tensions $\left(\mathrm{PaCO}_{2}\right)$, arterial oxygen tension $\left(\mathrm{PaO}_{2}\right)$, and 
oximetry parameters using a blood gas analyzer (ABL Model 700 System Radiometer, Copenhagen, Denmark).

Determinations of fasting plasma levels of protein IL-6 and $\mathrm{C}$-reactive protein (CRP) were implemented together with lactic acid measurements before and after IRB challenge. The fasting ethylenediaminetetraacetic acid (EDTA) venous blood samples were collected early in the morning (8-10 am). CRP was measured in duplicate by a high-sensitivity turbidimetric immunoassay (PETIA) (Siemens AG, Munich, Germany), with a lower detection limit of $0.5 \mathrm{mg} / \mathrm{L}$. Protein IL-6 was measured by an enzyme-linked immunosorbent assay kit (R\&D Systems, Minneapolis, MN, USA). Lactic acid in venous blood was measured in duplicate with the enzymatic colorimetric test kit (Siemens Diagnostics) using Dimension ${ }^{\circledR}$ RxL Max ${ }^{\circledR}$ clinical chemistry system (Siemens S.p.A., Milan, Italy.). Cytokine IL-1 $\beta$ and TNF- $\alpha$ were analyzed using Human Cytokine Bio-Plex Panel purchased by Bioclarma (Turin, Italy).

\section{Sample size determination and repeatability of main outcome measures}

The hypothesis of the study was that MBT delivered by a thermal-trained therapist was superior to unsupervised spa therapy (bath in hypermineral thermal water) in modulating/lowering change of IL-6 circulating levels after the IRB challenge.

Reportedly, IRB challenge increased IL-6 plasma levels from $5.30 \pm 1.02 \mathrm{pg} / \mathrm{mL}$ (resting level) to $10.33 \pm 2.14$ and $11.66 \pm 2.29 \mathrm{pg} / \mathrm{mL}$ in healthy individuals performing at $75 \%$ of their maximal inspiratory pressure, over one hour time. ${ }^{10}$ We judged clinically meaningful a between-groups difference of $2.5 \mathrm{pg} / \mathrm{mL}$ in our patients suffering from COPD and performing at $\approx 50 \%$ of maximal inspiratory pressure.

From a previous pilot study in 16 COPD subjects, the 1 -year repeatability of IL-6 averaged $0.34 \pm 1.68 \mathrm{pg} / \mathrm{mL}$. The $95 \%$ confidence interval (CI) of this change was CI: -0.08 to $0.72 \mathrm{pg} / \mathrm{mL}$.

A sample size of 32 individuals, 16 in each arm, was sufficient to detect a clinically important difference between groups. We were assuming a standard deviation of 1.68 using a twotailed $t$-test of difference between means with $80 \%$ power and a $5 \%$ level of significance. Considering a dropout rate of $\sim 20 \%$, the sample size required was 42 patients ( 21 per group).

\section{IRB challenge}

Experimental set up for IRB challenge consisted of a dedicated pressure threshold breathing device (Threshold
$\mathrm{IMT}^{\mathbb{Q}}$ Respironics) in series with the pneumotachograph of an open-circuit indirect calorimetry system (Sensor Medics). The dead space of the apparatus was $100 \mathrm{~mL}$.

Threshold IMT ${ }^{\circledR}$ Respironics is specifically designed to produce consistent inspiratory pressure loads regardless of the inspiratory flow rate. Inspiratory pressure load can vary from $-5 \mathrm{~cm} \mathrm{H}_{2} \mathrm{O}$ to $-41 \mathrm{~cm} \mathrm{H}_{2} \mathrm{O}$, by adjusting a spring-loaded poppet valve. The device flow capacity enables the patients to maintain a relatively constant inspiratory pressure load.

At baseline for 20 minutes, and during IRB challenge, we recorded breath by breath volume, flow, and breathing pattern $\left(T_{\mathrm{I}}, T_{\mathrm{E}}, T_{\mathrm{I}} / T_{\text {TOT }}, V_{\mathrm{T}}, V_{\mathrm{T}} / T_{\mathrm{I}}\right)$. We also measured oxygen consumption $\left(\mathrm{VO}_{2}\right)$, carbon dioxide production $\left(\mathrm{VCO}_{2}\right)$, mixed expired $\mathrm{CO}_{2}\left(\mathrm{PECO}_{2}\right)$, and end-tidal $\mathrm{CO}_{2}\left(\mathrm{PCO}_{2 \mathrm{ET}}\right)$.

Venous blood was sampled to measure changes in neuralimmunologic biomarkers. Oxygen saturation $\left(\mathrm{SpO}_{2}\right)$ was externally monitored by pulse oximeter (Biox 3700; Ohmeda, Boulder, CO, USA) with an ear probe.

The IRB challenge began with measuring subject inspiratory muscle strength at the maximum inspiratory pressure (MIP). It was obtained by a modification of the method of Black and Hyatt ${ }^{16}$ as implemented in the MasterScope ${ }^{\circledR}$ Body (VIASYS Healthcare $\mathrm{GmbH}$ ). The MIP was the average of the three highest measured values reproducible within 5\% of each other.

Eventually, the patient wearing nose clips set comfortably in a quiet environment and started breathing through the mouthpiece connected to the experimental set up without any added resistance. Then, a starting pressure load set at 50\% of patient's MIP was added. If this load was not sustainable for $>3$ minutes, it was reduced by $10 \%$. And, the patient attempted to perform additional runs to identify the sustainable inspiratory pressure (SIP).

Seat height and position remained constant for each subject during all studies to minimize variations in posture. Patients were highly motivated to endure as long as possible, and until exhaustion. They were coached and encouraged to perform maximally during inspiration, and to completely relax during expiration. They were free to choose their strategy to cope with the imposed pressure load and were free to adjust their breathing pattern.

ET was the time to task failure while performing repetitive contraction at a constant SIP. It was defined as the highest pressure the individual can generate in each breath for at least 12 consecutive minutes, and until exhaustion.

We took the SIP expressed as ratio PI/PI ${ }_{\text {max }}$ as an index of the mechanical load imposed on the inspiratory muscles (numerator) to the inspiratory force reserve (denominator). 
Oxygen consumption of IRB challenge was calculated as mean $\mathrm{VO}_{2 I R B}-$ meanVO $\mathrm{VRest}$, expressed as $\mathrm{mL} / \mathrm{min}$. The $\mathrm{O}_{2}$ expenditure of the respiratory muscles endurance $\left(\mathrm{VO}_{2 \mathrm{Endur}}\right)$ was the difference between total body $\mathrm{O}_{2}$ consumption during inspiratory resistive breathing challenge and resting ventilation, expressed as $\mathrm{mL} / \mathrm{min}$. It was calculated as the difference between cumulative $\mathrm{VO}_{2 \mathrm{IRB}}-\left(\mathrm{VO}_{2 \mathrm{Rest}} \mathrm{ET}\right)$.

\section{Statistical analysis}

Descriptive statistics is given as mean (standard deviation) or as a percentage value for continuous and the respective categorical variables. The distribution of continuous variables was tested for normality by the Shapiro-Wilk test. Nonnormally distributed variables were transformed in natural logarithm units.

Between-groups baseline comparisons were carried out with a one-way analysis of variance (ANOVA) or chi-square test if the examined variable was continuous or, respectively, categorical.

To test for the effects of thermal interventions, we made repeated measurements at the same times (before/after IRB challenge) on groups of individuals receiving treatment or comparator. It was an experiment with a nested (hierarchical) structure and two effects variables: 1) thermal interventions and 2) IRB challenge. Random-effects ANOVA from this experiment was computed by SAS/STAT ${ }^{\circledR} 9.2$ (Proc. Reg, SAS/STAT-SAS Institute Inc., Cary, NC, USA). We tested the effects of thermal interventions on the main outcome variables IL-6 and ET, together with the systemic biomarkers panel and lactic acid.

We used analysis of covariance (ANCOVA) analysis to test for differences in the relationship of $\Delta \mathrm{IL}-6$ upon $\mathrm{VO}_{2 \mathrm{Endur}}$ between thermal intervention groups, after adjusting for before-intervention $\mathrm{VO}_{2 \mathrm{Endur}}$. Also, we used the general linear model analysis to evaluate the effect of IL- 6 and respiratory rate (RR) on $T_{\text {I_IRB }}$ after thermal interventions.

All tests were two-tailed, and $P<0.05$ was considered statistically significant.

\section{Results}

Figure 1 details the flow diagram for patients' allocation to the intervention groups. At the intake phase of the protocol, before moving to eligibility screening and the run-in phase of the randomized clinical trial, all the patients underwent clinical-functional screening, and many individuals faced the problem of dealing with a presumptive COPD diagnosis, which may not have been systematically checked in primary clinical care. Consequently, the patients who had primary lung conditions other than COPD were not eligible for enrollment to the study.

Table 1 shows anthropometrics, smoking habit, and pulmonary function data in 42 COPD patients. Before thermal interventions, the two groups were comparable for age, smoking habit, body mass index, and pulmonary function data. Pack-years (cigarettes/day/20 years of smoking) had a skew distribution with a median of 40.5 (95\% CI: 28.0-46.2).

As shown in Table 2, there were no statistically significant differences in natural log-transformed IL-6, CRP, cytokine IL-1 $\beta$, TNF- $\alpha$, and ACTH and lactic acid determinations between groups, before thermal interventions. Similarly, there was no statistically significant difference between the groups in MIP, SIP, and ET at baseline.

Table 3 summarizes accountability of patients' attendance to treatment/comparator, their adherence to scheduled sessions, and effects of treatment/comparator on mean $\mathrm{SaO}_{2}$ both before and after each thermal intervention. There were no serious adverse events reported. Two nonserious adverse events occurred in the MBT group: one patient experienced herpes zoster recurrence and gave up mudpack applications after eight sessions of regular attendance, while one patient experienced a COPD exacerbation after regular attendance to 12 sessions of mudpack applications. Mean $\mathrm{SpO}_{2}$ appears slightly higher in the MBT group compared to the LTA group, although this difference attains statistical significance only at baseline.

Table 4 shows the mechanical responses to IRB challenge between and within groups, and pre- and postthermal interventions.

To perform the IRB challenge, SIP was initially set at $50 \%$ of MIP. Eight patients out of 42 were able to endure while faced with this inspiratory threshold load before thermal interventions and seven out of 41 after thermal interventions. The SIP averaged $34.2 \mathrm{~cm} \mathrm{H}_{2} \mathrm{O}, 95 \%$ CI: $31.8-36.6 \mathrm{~cm}$ $\mathrm{H}_{2} \mathrm{O}$ that is $41.3 \%$ of MIP, $95 \%$ CI: $36.7 \%-43.9 \%$ before, and, respectively, $36.2 \mathrm{~cm} \mathrm{H}_{2} \mathrm{O}, 95 \% \mathrm{CI}: 33.8-38.5 \mathrm{~cm} \mathrm{H}_{2} \mathrm{O}$ that is $40.2 \%$ of MIP, $95 \%$ CI: $37.0 \%-43.4 \%$ after thermal interventions.

The analysis of patterns of ventilation in response to IRB revealed great variability in inspiratory time from subject to subject when breathing with a freely adopted pattern of breathing. A statistically significant effect of IRB challenge existed before and after thermal interventions $(P<0.0001)$ without any significant treatment-by-trial interaction.

Before thermal interventions, $T_{\text {IIRB }}$ significantly increased over baseline by a mean difference of 0.633 seconds $(95 \%$ CI: $0.389-0.937), P<0.0001)$ and $V_{\text {T_IRB }}$ increased by a mean 


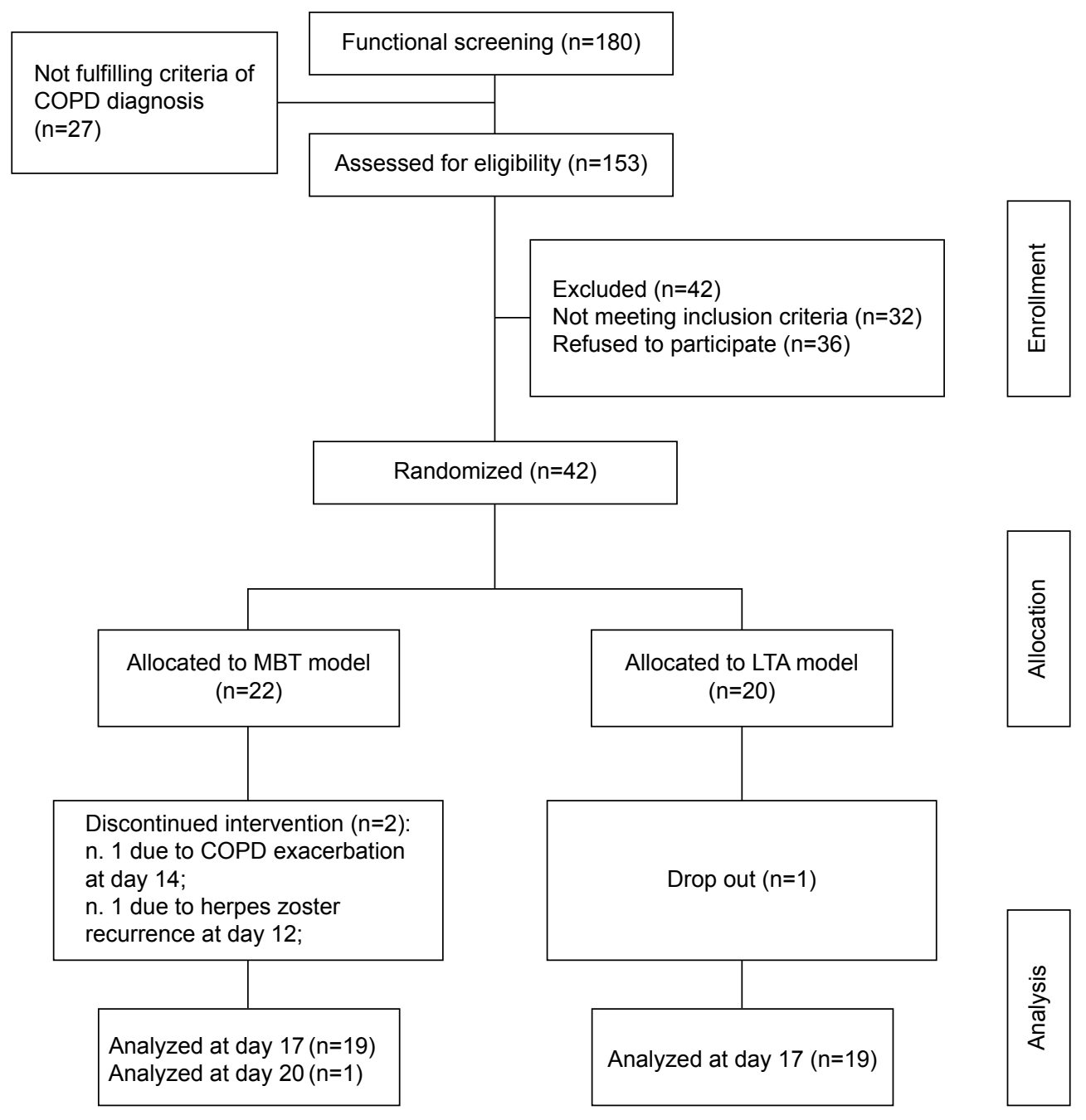

Figure I Flow diagram of patients' allocation to the thermal interventions. Abbreviations: LTA, leisure thermal activity; MBT, mud bath therapy.

Table I Anthropometrics, smoking habit, and pulmonary function data in 42 COPD patients according to treatment/comparator allocation

\begin{tabular}{|c|c|c|c|c|c|}
\hline \multirow{2}{*}{$\begin{array}{l}\text { Intervention } \\
\text { Patients }\end{array}$} & \multicolumn{2}{|c|}{ MBT group, $n=22$} & \multicolumn{2}{|c|}{ LTA group, $n=20$} & \multirow[t]{2}{*}{$P$-value ${ }^{a}$} \\
\hline & Mean & $95 \% \mathrm{Cl}$ & Mean & $95 \% \mathrm{Cl}$ & \\
\hline Age, years & 64.8 & $61.2-68.5$ & 64.4 & $60.2-67.8$ & 0.75 \\
\hline Sex, male:female & {$[18: 4]^{b}$} & - & {$[15: 5]^{\mathrm{b}}$} & - & 0.71 \\
\hline Smoking habit, C:F:NS & $\{8: 12: 0\}^{c}$ & - & $\{9: \mid 1: 0\}^{c}$ & - & 0.36 \\
\hline $\mathrm{BMI}, \mathrm{kg} / \mathrm{m}^{2}$ & 31.0 & $27.6-34.5$ & 30.8 & $27.1-34.4$ & 0.92 \\
\hline $\mathrm{FEV}_{1}, \%$ pred & 70.7 & $65.4-76.0$ & 65.8 & $60.2-71.3$ & 0.20 \\
\hline VC, \% pred & 98.4 & $90.7-106.1$ & 97.5 & $89.5-105.6$ & 0.88 \\
\hline $\mathrm{FEV}_{\mathrm{l}} / \mathrm{VC}, \%$ & 56.0 & $51.7-60.4$ & 55.7 & $50.2-59.4$ & 0.69 \\
\hline TLC, \% pred & 102.3 & $95.5-109.1$ & 103.4 & $96.3-110.6$ & 0.82 \\
\hline FRC, \% pred & 113.1 & $100.2-125.9$ & 120.9 & $107.4-134.4$ & 0.41 \\
\hline RV, \% pred & 113.4 & $97.5-129.3$ & 122.5 & $105.8-139.2$ & 0.43 \\
\hline DLCO/VA, \% pred & 67.3 & 57.8-77.I & 56.9 & $46.4-67.5$ & 0.16 \\
\hline $\mathrm{MIP}, \mathrm{cm} \mathrm{H} \mathrm{H}_{2} \mathrm{O}$ & 88.8 & $80.8-96.8$ & 79.2 & $70.4-87.6$ & 0.10 \\
\hline $\mathrm{PaO}_{2}, \mathrm{kPa}$ & 10.2 & $9.8-10.6$ & 9.6 & $9.2-10.0$ & 0.06 \\
\hline $\mathrm{PaCO}_{2}, \mathrm{kPa}$ & 4.8 & $4.5-5.0$ & 5.0 & $4.8-5.2$ & 0.14 \\
\hline
\end{tabular}

Notes: ${ }^{\text {a }}$-value. ${ }^{\mathrm{b}}$ Counts in square brackets are compared by Fisher's exact test. 'Counts in curly brackets are compared by $\chi^{2}$.

Abbreviations: BMI, body mass index; C, current smoker; Cl, confidence interval; COPD, chronic obstructive pulmonary disease; DLCO/VA, CO-diffusing capacity to alveolar volume ratio; F, former smoker; FEV , forced expiratory volume in one second; FEV /VC, Tiffeneau index; FRC, functional residual capacity measured by body box; LTA, leisure thermal activity; MBT, mud bath therapy; MIP, maximum inspiratory pressure, pressure can be generated against an occluded airway beginning at functional residual capacity; NS, non smoker; RV, residual volume; TLC, total lung capacity; VC, slow vital capacity. 
Table 2 Between-groups comparison in endpoint and exploratory variables, at baseline

\begin{tabular}{|c|c|c|c|c|c|}
\hline \multirow{2}{*}{$\begin{array}{l}\text { Intervention } \\
\text { Endpoint }\end{array}$} & \multicolumn{2}{|c|}{ MBT group, n=22 } & \multicolumn{2}{|c|}{ LTA group, $n=20$} & \multirow[t]{2}{*}{$P$-value ${ }^{a}$} \\
\hline & Mean & $95 \% \mathrm{Cl}$ & Mean & $95 \% \mathrm{Cl}$ & \\
\hline IL-6, Ln & 0.95 & $0.56-1.34$ & 1.30 & $0.928-1.666$ & 0.25 \\
\hline ET, minutes & 26.95 & 19.94-27.95 & 23.95 & 19.94-27.95 & 0.24 \\
\hline \multicolumn{6}{|l|}{ Exploratory } \\
\hline CRP, Ln ${ }^{b}$ & 1.47 & $1.09-1.84$ & 1.56 & $1.10-2.02$ & 0.76 \\
\hline ACTH, $\mathrm{Ln}^{\mathrm{b}}$ & 3.09 & $2.85-3.34$ & 3.31 & $3.04-3.58$ & 0.28 \\
\hline IL-I $\beta,[I R: O O R<]^{c}$ & [B: 2:20] & [A: 2:20] & [B: I:19] & [A: I:I8] & $\{3.1-43.3 \mathrm{pg} / \mathrm{mL}\}^{\mathrm{d}}$ \\
\hline TNF- $\alpha,[\text { IR:OOR }<]^{c}$ & [B: 3:19] & [A: 4:18] & [B: 2:18] & {$[A: 2: 17]$} & $\{15.8-379.9 \mathrm{pg} / \mathrm{mL}\}^{\mathrm{d}}$ \\
\hline Lactate $_{\text {before_IRB }}$ & 1.58 & $1.21-1.94$ & 1.31 & $1.01-1.61$ & 0.24 \\
\hline Lactate $_{\text {after_IRB }}$ & 1.37 & $1.18-1.56$ & 1.22 & $0.96-1.47$ & 0.32 \\
\hline MIP, $\mathrm{cm} \mathrm{H}_{2} \mathrm{O}$ & 88.8 & $80.78-96.82$ & 79.2 & 70.74-87.57 & 0.10 \\
\hline SIP, $\mathrm{cm} \mathrm{H}_{2} \mathrm{O}$ & 35.53 & $31.89-39.17$ & 32.25 & $27.96-35.61$ & 0.16 \\
\hline SIP/MIP, \% & 41.58 & $37.95-45.22$ & 41.26 & $41.03-44.84$ & 0.88 \\
\hline
\end{tabular}

Notes: a ${ }^{P}$-value. ${ }^{b}$ Natural logarithm units. ${ }^{\mathrm{I}} \mathrm{R}$ indicates in range of the titration curve and $\mathrm{OOR}<$ indicates out of range, and below the lower limits of the titration curve. The numbers in square brackets are IR:OOR < ratios, as both cytokines were undetectable in the majority of patients either before [B] or after [A] thermal interventions. dStandard reference range in curly brackets is reported as $\mathrm{pg} / \mathrm{mL}$.

Abbreviations: ACTH, adrenocorticotrophin hormone; $\mathrm{Cl}$, confidence interval; CRP, C-reactive protein; ET, endurance time; IL-6, interleukin 6; IL-I $\beta$, interleukin I-beta; LTA, leisure thermal activity; MBT, mud bath therapy; MIP, maximum inspiratory pressure; SIP, sustainable inspiratory mouth pressure, in $\mathrm{cm}^{\mathrm{H}} \mathrm{O}_{2} \mathrm{O}$, and as SIP/ ${ }_{\text {imax }} \%$; TNF- $\alpha$, interleukin tumor necrosis factor alfa.

difference of $124 \mathrm{~mL}(95 \% \mathrm{CI}: 0.057-0.191)$. The increase in duty cycle $\left(T_{\mathrm{I}} / T_{\text {тот }}\right)$ by a mean difference of $15.4 \%(95 \% \mathrm{CI}$ : $12.3-18.5)(P<0.0001)$ indicated that the changes in $T_{\mathrm{I}}$ were of larger magnitude that the changes in the RR that increased by a mean difference of 0.508 ( $95 \% \mathrm{CI}:-1.48$ to 2.50 ), and in fact did not attain statistical significance $(P=0.609)$. Minute ventilation $\left(V_{\mathrm{E}}\right)$ increased by a mean difference of $2.36 \mathrm{~L} / \mathrm{m}$ (95\% CI: 1.36-3.36) $(P<0.0001)$.

After thermal interventions, $T_{\text {I_IRB }}$ significantly increased over baseline by a mean difference of 0.445 seconds $(95 \%$ CI: $0.201-0.689), P<0.001)$ and $V_{\text {T_IRB }}$ increased by a mean difference of $172 \mathrm{~mL}$ (95\% CI: 0.84-0.261). Neither increase in duty cycle $\left(T_{\mathrm{I}} / T_{\mathrm{TOT}}\right)$ by a mean difference of $5.7 \%(95 \%$ CI: -8.6 to 19.9$)$ nor change in RR that increased by a mean difference of 0.903 (95\% CI: -1.19 to 2.99$)$ attained statistical significance ( $P=\mathrm{ns}$ for both). Minute ventilation $\left(V_{\mathrm{E}}\right)$ increased by a mean difference of $2.74 \mathrm{~L} / \mathrm{m}(95 \% \mathrm{CI}$ : 1.65-3.84) $(P<0.0001)$.

Table 4 illustrates also the average oxygen consumption of IRB challenge $\left(\mathrm{VO}_{2 \_ \text {IRB }}\right)$, which was not significantly different between the groups. Cohen's $d$ was 0.31 , and effect size was small (0.15).

Figure 2 shows the within- and between-groups changes in cytokine IL-6. Repeated-measures ANOVA indicates no significant interaction between treatment and IRB trials on cytokine IL-6 response to IRB challenge (degrees of freedom: 38, MS : $0.9077, P=0.3119)$, but a statistically significant effect of IRB trials (degrees of freedom: 38, MS : 0.1799, $P<0.0005$ ), leading the statistically significant increase in $\triangle \mathrm{IL}-6$ in both MBT group and LTA group after thermal

Table 3 Baseline characteristics, accountability of adverse events, and adherence to thermal spa therapy and mud packs interventions

\begin{tabular}{|c|c|c|c|}
\hline Intervention & MBT group, $n=22$ & LTA group, $n=20$ & $P$-value ${ }^{a}$ \\
\hline \multicolumn{4}{|l|}{ Patients } \\
\hline $\mathrm{N}$ started (completed) & $22(22)$ & $20(19)$ & - \\
\hline Sex, male/female & $18 / 4$ & $15 / 5$ & - \\
\hline Age (standard deviation) & $63.7(6.7)$ & $65.0(9.6)$ & 0.643 \\
\hline SAE & No & No & \\
\hline$N_{S A E}^{b}$ & $2 / 22$ & No & \\
\hline PTPA, R:NR & $18: 2$ & $15: 4$ & \\
\hline Adherence to balneotherapy ${ }^{a}, \%$ & $58.9(30.5)$ & $74.3(24.8)$ & 0.083 \\
\hline Adherence to mud packs,$\%$ & $97.4(7.9)$ & NA & - \\
\hline $\mathrm{SpO}_{2} \%$ before treat./comp. & $95.8(1.4)$ & $94.6(1.8)$ & 0.034 \\
\hline $\mathrm{SpO}_{2} \%$ after treat./comp. & $95.4(1.4)$ & $94.6(2.3)$ & 0.203 \\
\hline
\end{tabular}

Notes: No SAE reported; NSAE, one herpes virus recurrence, and I chronic obstructive pulmonary disease exacerbation in MBT group. ${ }^{2}$ Number of balneotherapy sessions

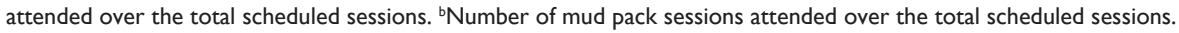

Abbreviations: MBT, mud bath therapy; NR, number of the patients not attending on a regular basis; NSAE, nonserious adverse event; PTPA, patients' attendance to thermal pool; R, number of the patients attending on a regular basis; SAE, serious adverse event; NA, not applicable. 


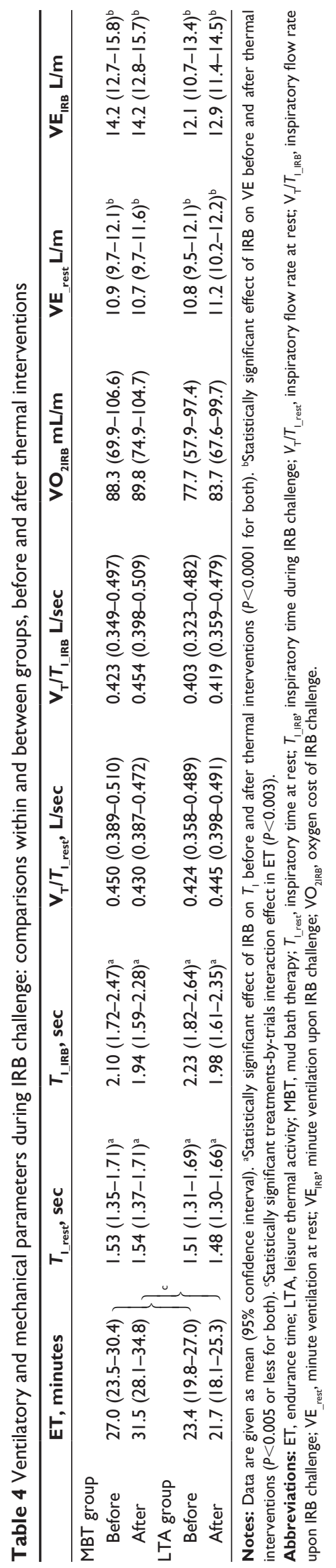

interventions. Cohen's $d$ was -0.169 , and effect size was small (-0.08).

Figure 3 shows the within- and between-groups changes in loaded breathing tolerance as reflected by ET. The twofactor ANOVA, for repeated measurements, indicated a statistically significant interaction effect of treatment by time. The ET increased by 4.5 minutes after MBT, compared with a -2.3 -minute reduction after LTA model $(P<0.01)$. Cohen's $d$ was 1.04 , and effect size was large (0.46).

IRB challenge elicited a fair reduction in plasma lactic acid both before and after thermal interventions. Between-groups mean difference $(\delta)$ and $95 \%$ CI were $-0.16(-0.27$ to 0.58$)$ pre- and -0.30 ( -0.82 to 0.22 ) postthermal interventions.

Figure 4 shows the mean differences (within-group difference) in ACTH $(\triangle \mathrm{ACTH})$ and $\mathrm{CRP}(\triangle \mathrm{CRP})$ induced by IRB challenge in MBT and LTA groups. For ACTH measurements, Cohen's $d$ was 0.44 , and effect size 0.218 . For CRP, Cohen's $d$ was 0.668 and the effect size was 0.317 , which indicates the percent of nonoverlap of the MBT group's scores with those of the LTA group. So, the effect size of trial change was small for ACTH and medium for CRP. Before thermal interventions, no relationship existed between $\triangle \mathrm{ACTH}$ and $\triangle \mathrm{IL}-6(r: 0.069, P: 0.10)$ and between $\triangle \mathrm{CRP}$ and $\Delta \mathrm{IL}-6(r: 0.045, P: 0.77)$, respectively. After thermal interventions, no relationship existed between $\triangle \mathrm{ACTH}$ and $\Delta \mathrm{IL}-6(r: 0.032, P: 0.87)$ and between $\Delta \mathrm{CRP}$ and $\Delta \mathrm{IL}-6$ $(r: 0.12, P: 0.44)$, respectively. These data are not shown.

To explore the homeostatic perturbations possibly leading to the increase in endurance of loaded inspiratory muscles, we analyzed the relationship between $\Delta \mathrm{IL}-6$ and $\mathrm{VO}_{2 \mathrm{Endur}}$ between the intervention groups over IRB challenges. The relationship was supposed to reflect reliance on anaerobic and aerobic metabolic substrates. When, after-intervention $\Delta \mathrm{IL}-6$ IRB and before-intervention $\mathrm{VO}_{2 \mathrm{Endur}}$ were used as covariates in ANCOVA analysis with after-intervention $\mathrm{VO}_{\text {2Endur }}$ as the dependent variable, the difference between the groups was significant $(P<0.002)$ as were the covariates $\Delta \mathrm{IL}-6_{\text {IRB }}(P<0.001)$ and $\mathrm{VO}_{2 \text { Endur }}(P<0.001)$. Between thermal interventions, the $\mathrm{VO}_{2 \text { Endur }}$ increased by $0.229 \mathrm{Ln}$ units after MBT, compared with a $-0.372 \mathrm{Ln}$ units reduction after LTA model $(P=0.01)$. Cohen's $d$ was 0.83 , and the effect size was large (0.38). Furthermore, the slope for the covariate relationship between the dependent variable and $\Delta \mathrm{IL}-6$ was statistically significant in the MBT group $(P<0.001)$ but not in the LTA group.

Table 5 shows the relationship between $T_{\text {IIRB }}$ and $\Delta \mathrm{IL}-6$ and RR in MBT and LTA before and after thermal interventions. The thermal intervention categories did not affect the model. Before thermal interventions, $\Delta \mathrm{IL}-6$ and RR 


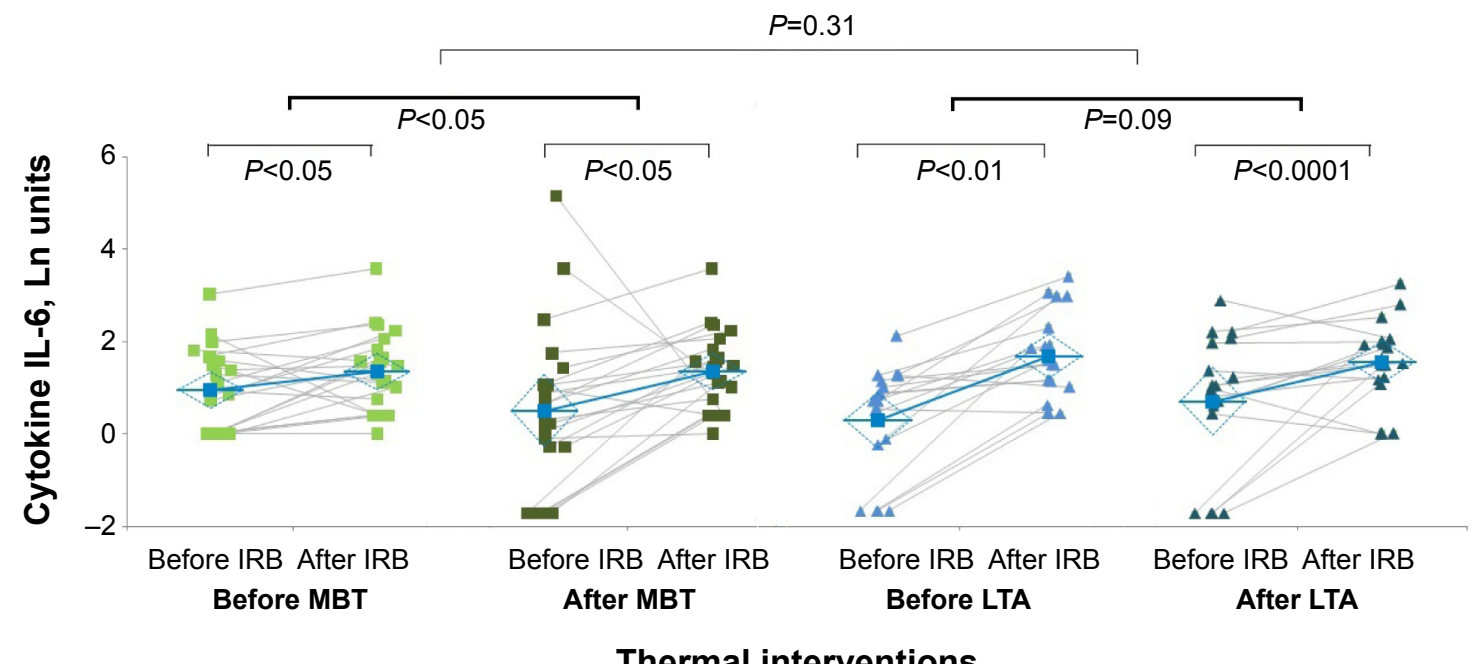

Figure 2 IRB challenge-induced changes in $\Delta \mathrm{IL}-6$ (within groups) before and after thermal interventions (between groups).

Notes: The effect size was small for $\Delta \mathrm{IL}-6(-0.08)$. Individual measurements and mean value in MBT group before thermal interventions (light green squares) and after thermal interventions (dark green squares). Individual measurements and mean value in LTA group before thermal interventions (light blue triangles) and after thermal interventions (dark green triangles).

Abbreviations: IL-6, interleukin 6; IRB, inspiratory resistive breathing; LTA, leisure thermal activity; MBT, mud bath therapy.

accounted, respectively, for $31 \%$ and $68 \%$ of variability about the regression in all the patients $(P<0.01$ or less). After thermal interventions, RR accounted for $79 \%$ of variability about the regression $(P<0.0001)$, while $\Delta \mathrm{IL}-6$ contributed for just $17 \%$ and was not significant anymore $(P: 0.07)$. These data might reflect a better readiness to cope with the inspiratory loaded breathing task.

\section{Discussion}

\section{Interpretation of results}

HT is a widely used option of nonpharmacologic treatment in modern health care systems. It is classified under the label of traditional medicine as specified in the World Health Organization Guideline in the Strategies for Traditional Medicine 2014-23. ${ }^{17}$ Nevertheless, implementation of the best quality studies to validate hydrology therapies as a cure for systemic inflammatory manifestations remains a challenge for research funding institutions in a range of chronic disease conditions like COPD.

The novelty of the trial was to look at both thermal interventions as passive warm-up routines and to test their effects on immunologic (cytokine) response upon a moderated loaded breathing challenge and, further, to explore the effects on loaded inspiratory muscle endurance and explain

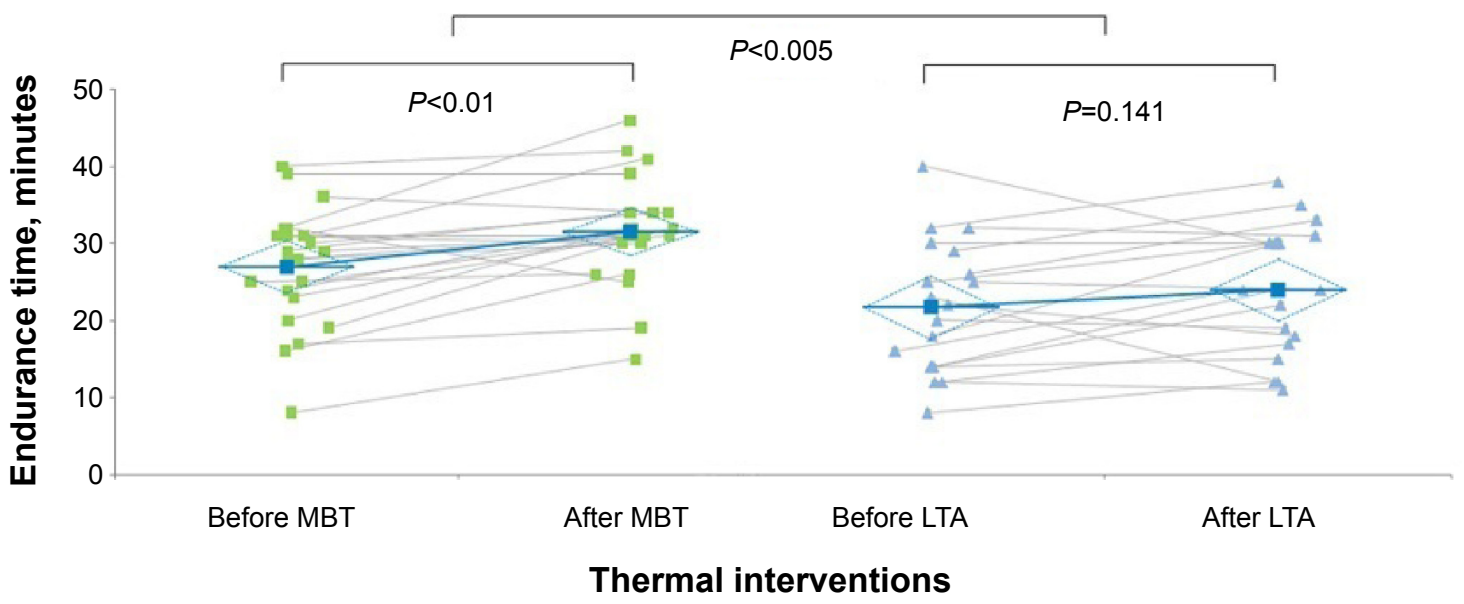

Figure 3 IRB challenge-induced changes in ET (within groups) before and after thermal interventions (between groups).

Notes: The effect size was moderate for ET The effect size was large for ET (0.47). Individual measurements in MBT group before and after thermal interventions (green squares) and mean values. Individual measurements in LTA group before and after thermal interventions (blue triangles) and mean values. Abbreviations: ET, endurance time; IL, interleukin; IRB, inspiratory resistive breathing; LTA, leisure thermal activity; MBT, mud bath therapy. 

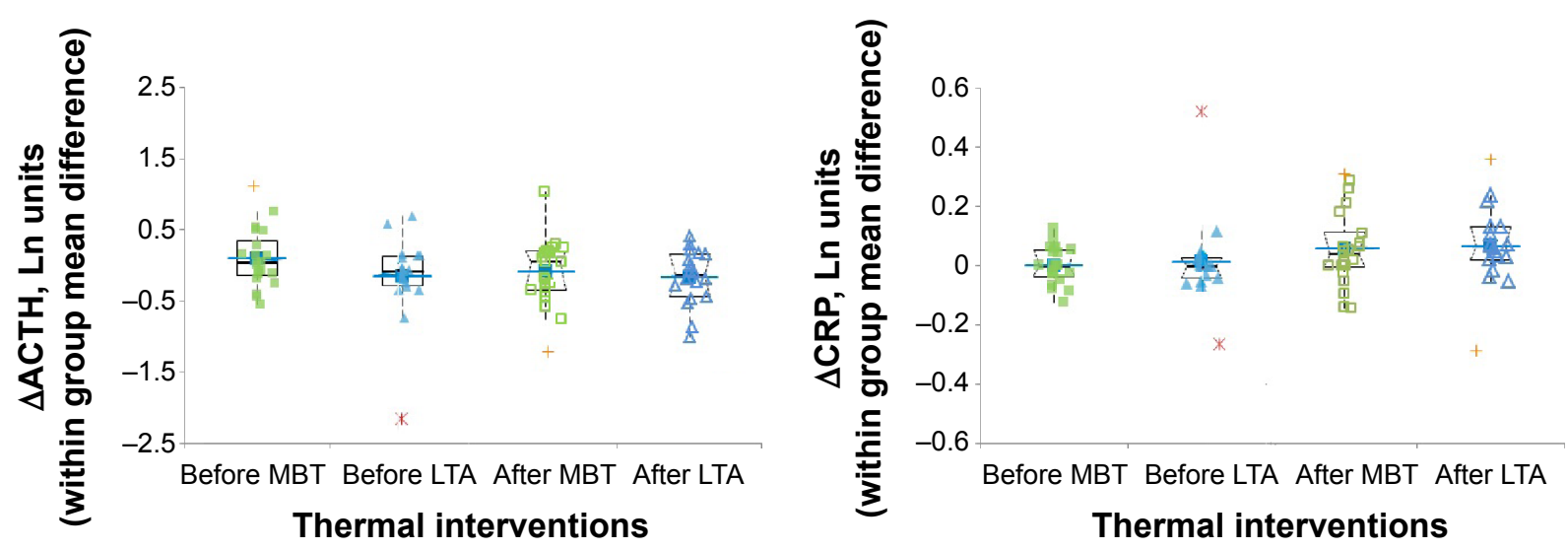

$$
\text { - Near outliers * Far outliers }
$$

Figure 4 IRB challenge-induced changes in ACTH $(\triangle A C T H)$ and CRP $(\triangle C R P)$ before and after thermal interventions (box plots).

Notes: Left panel: within-group mean difference in ACTH. Right panel: within-group mean difference in CRP. The box plots are superimposed to the dot plots. Closed and open squares indicate IRB-induced changes before and after MBT interventions, respectively, while closed and open triangles are IRB-induced changes before and after LTA interventions, respectively. Mean lines, single outlier, and extreme values are also reported as indicated by the legend.

Abbreviations: ACTH, adrenocorticotrophic hormone; CRP, C-reactive protein; IRB, inspiratory resistive breathing; LTA, leisure thermal activity; MBT, mud bath therapy.

the homeostatic adaptations leading to the increase in ET in the treatment group. To this end, we analyzed the covariate relationship between cytokine IL-6 and endurance oxygen expenditure of loaded inspiratory muscles.

According to Vassilakopoulos et $\mathrm{al}^{12}$ the immunologic effects of loaded breathing result in stimulation of HPA axis and particularly in upregulation of cytokine IL-6. The effects occurred in healthy subjects breathing strenuously against a load set at $75 \%$ of their maximal inspiratory pressure, but not in healthy individuals breathing against a moderate load.

Fuster et $\mathrm{al}^{18}$ found that patients with COPD and very severe airflow obstruction failed mounting an appropriate

Table 5 Relationship between $T_{\text {I_IRB }}$ and $\Delta \mathrm{IL}-6_{\mathrm{IRB}}$ and $\mathrm{RR} \mathrm{R}_{\mathrm{IRB}}$ before and after thermal interventions

\begin{tabular}{lllll}
\hline Parameter & Standardized beta & $\boldsymbol{t}$ & $\mathbf{D F}$ & $\boldsymbol{P}$-value \\
\hline $\boldsymbol{R}^{2}: \mathbf{0 . 6 1 9}$ & & & & \\
Constant & 0 & 12.68 & 36 & $<0.000 \mathrm{I}$ \\
MBT group & - & - & 36 & - \\
LTA group & - & -1.46 & 36 & 0.1534 \\
$\Delta \mathrm{IL}-6_{\mathrm{IRB}}$ before & -0.306 & -2.83 & 36 & 0.0075 \\
$\mathrm{RR}_{\mathrm{IRB}}$ before & -0.677 & -5.83 & 36 & $<0.000 \mathrm{I}$ \\
$\boldsymbol{R}^{2}: \mathbf{0 . 6 9 8}$ & & & & \\
Constant & 0 & 15.92 & 37 & $<0.000 \mathrm{I}$ \\
MBT group & - & - & 37 & - \\
LTA group & - & -1.40 & 37 & 0.1704 \\
$\Delta \mathrm{IL}-6_{\mathrm{IRB}}$ after & -0.173 & -1.86 & 37 & $0.07 \mathrm{I}$ \\
RR $_{\mathrm{IRB}}$ after & -0.788 & -8.32 & 37 & $<0.000 \mathrm{I}$ \\
\hline
\end{tabular}

Abbreviations: $\mathrm{RR}_{\mathrm{IRB}}$, respiratory rate during IRB challenge; $\Delta \mathrm{IL}-6_{\mathbb{R B}}$, cytokine 6 change over baseline during IRB challenge; IRB, inspiratory resistive breathing; LTA, leisure thermal activity; MBT, mud bath therapy; $T_{\perp \perp R B}$, inspiratory time during IRB challenge; DF, degree of freedom. anti-inflammatory response to the maximal inspiratory loading test. ${ }^{19}$ In agreement with these authors, we were not able to measure any simultaneous HPA axis stimulation as assessed by increase in either cytokine IL- $1 \beta$ or ACTH plasma levels. Nevertheless, we documented a timely (within 40 minutes) and statistically significant increase in cytokine IL-6 response in our patients. They performed against an inspiratory threshold load set at $\approx 40 \%$ of their maximal inspiratory pressure, both before and after thermal interventions.

Differences in maximal inspiratory loading test, compared to our endurance test, timing of venous blood sample collection and differences in severity of airflow obstruction make it difficult to compare the present results with those of Fuster et al. ${ }^{18}$ On the other hand, the change of IL- 6 over its baseline value ( $\Delta \mathrm{IL}-6)$ was pretty inconsistent among patients suffering from COPD in comparison to the change observed in healthy individuals performing strenuously against high inspiratory loads. The coefficient of variation of our patients was just over five-folds as high as the coefficient of variation of healthy subjects studied by Vassilakopoulos et al ${ }^{12}$ (COPD coefficient of variation: $115 \%$ vs healthy coefficient of variation: $20 \%$ ). Moderate intensity of inspiratory resistive breathing might have been the cause of the milder and inconsistent increase in cytokine IL-6 over its baseline value. Also, the fact that our COPD patients volitionally stopped exercising within 40 minutes and were unable to endure behind this failure point might have been responsible for the lack of HPA axis stimulation. Reportedly, changes in ACTH plasma levels lagged $\sim 15$ minutes behind failure point, ie, the time point when resistive load cannot be sustained anymore. ${ }^{12}$ 
A thorough examination of the immunological signaling of these responses is beyond the aims of the present study. So, it remains a matter of speculation whether the milder upregulation of cytokine IL-6 was dependent on moderate intensity of IRB challenge and whether the inability to perform behind the failure point until the exhaustion point might have prevented HPA axis activation among patients suffering from COPD. Alternatively, these responses would have been relevant to different stimuli within respiratory muscles because the stimuli responsible for increased proinflammatory cytokine production during inspiratory resistive loading remain elusive. ${ }^{13}$

In theory, the failure, to stimulate HPA axis, would have resulted from impaired sympatho-corticotrophic axis outflow. Lately, Iranmanesh et $\mathrm{al}^{20}$ suggested this hypothesis after they compared responses to incremental bicycle ergometer in COPD patients with no exposure to corticosteroids within 3 months and in healthy subjects. They documented no increase in peak ACTH, cortisol, and epinephrine in response to cycling at both maximal and submaximal levels; in addition, patients performing at submaximal levels showed failure to regularize ACTH secretion pattern. It is conceivable that an impaired corticosteroid feedback would have also occurred in our COPD patients, who were regularly taking maintenance inhaled corticosteroid medications.

The second result of the trial was the significantly higher ET in patients allocated to treatment than in those allocated to comparator. Central to the interpretation of this effect is the observation that elongation of ET occurred while enduring against a submaximal inspiratory load, which is defined as an exercise requiring less than $\mathrm{VO}_{2 \max }$. Under this condition, it seemed unlikely that improved delivery of $\mathrm{O}_{2}$ to respiratory muscles was responsible for the increased endurance. On the contrary, it would have been consistent with the occurrence of a training effect brought about by the metabolic consequences of biochemical adaptations in respiratory muscles. They were represented by the increase in oxygen expenditure due to ET elongation and plasma lactate after IRB challenge and presumably slower utilization of carbohydrates, as assessed by $\Delta \mathrm{IL}-6_{\mathrm{IRB}}$.

To the best of our knowledge, this is the first time that IL-6 production during resistive breathing is regarded as a predictor of respiratory muscle metabolic adaptations in response to a nonpharmacological thermal intervention such as MBT model. And, there is considerable interest regarding the mechanisms, which can elicit increase in ET in response to packs with medicinal clays. Eventually, the achievement of a training effect using a passive warm-up routine is of vital importance in patients suffering from COPD. It could represent a smart strategy for treating the effects of deconditioning that often limits the success of traditional rehabilitative options.

Previous studies ${ }^{21,22}$ in both rat model and human beings have provided indirect evidence for muscle mitochondria adaptations to training of adequate intensity. Lately, studies conducted using saponin-skinned fiber oxygraphic technique showed the higher capacity for in situ mitochondria of respiratory muscles to generate $\mathrm{ATP}^{23}$ and higher efficiency of ATP production and changes in energy distribution within patients with COPD, who chronically experience an endurance training-like effect. ${ }^{24}$ However, the significant increase in ET we documented was not the result of an active strenuous muscle contraction training. Instead, it probably resulted from the temperature effect and possibly chemical and biochemical properties of mature medicinal clays applied on the body skin for 2 weeks. And, we feel quite confident to exclude that the use of a single session of threshold IMT before thermal interventions and 2 weeks later would have had adequate intensity and duration to elicit the hypothesized biochemical changes. Overall, training effects have been reported in response to strenuous endurance exercise carried out for $>1 \mathrm{~h} / \mathrm{d}$ over a period of time exceeding 2 weeks in elite runners. ${ }^{25}$

Brooks et $\mathrm{al}^{26}$ measured the relationship between temperature and mitochondrial respiration in isolated rat skeletal muscle in vitro at temperatures between $37^{\circ} \mathrm{C}$ and $45^{\circ} \mathrm{C}$. They reported an increase in nonconservative mitochondrial respiratory state (state 4) and suggested the possibility for metabolic effects to occur due to the well-known effect of temperature on the rates at which biochemical reactions proceed. Lately, Power et $\mathrm{al}^{27}$ used a new technique for the measurement of ATP consumption in real time and confirmed previous in vitro findings. Therefore, under the high state 4 respiration at $\sim 40^{\circ} \mathrm{C}$, the ATP production seems not to increase with increasing temperature, despite the increased energy demand. The ATPase stimulation favors the reaction to proceed toward generation of ADP and inorganic phosphate to result in higher oxygen consumption and potentially in a certain reduction of ADP:O ratio.

The clinical rehabilitation setting of the study prevented the possibility of using dedicated laboratory techniques to ascertain the biochemical mechanisms of energetic adaptations occurring at the subcellular mitochondrial level. Nevertheless, $\mathrm{LnVO}_{2 \mathrm{Endur}} / \Delta \mathrm{IL}-6_{\mathrm{IRB}}$ relationship we measured during IRB challenge can be regarded as a clinical biomarker of the respiratory-metabolic adaptations, which occurred after exposure to the high temperature of packs with medicinal clays. 
After thermal interventions, the higher oxygen expenditure during endurance suggested better $\mathrm{O}_{2}$ utilization to cope with muscle's need for energy because it resulted from an increase in ET while average $\mathrm{VO}_{2}$ did not change. In addition, the results of ANCOVA analysis indicated that the higher $\mathrm{VO}_{2 \mathrm{Endur}}$ in patients allocated to MBT model is predicted by $\Delta \mathrm{IL}-6_{\text {IRB }}$ when adjusting for baseline respiratory oxygen cost. To the extent that muscle-derived IL- 6 can be regarded as a hormone-like glucose-regulatory mechanism and a signal of critical low levels of glycogen content to the working muscles, ${ }^{28,29}$ its rise upon the IRB challenge after the passive warm-up sessions of medicinal clays would be taken as an indirect sign of lower glycogen utilization or slower glycolysis activation in respiratory muscles during IRB challenge.

There is no contrast between these results and currently available evidence in patients suffering from COPD that the primary factor regulating diaphragm and inspiratory muscles oxidative capacity is the high concentration of phosphate acceptor ADP. ${ }^{24}$ Thus, it is conceivable that the moderate IRB challenge performed after muscle warm-up with medicinal clays acted as an input signal to the respiratory oxidative muscles fibers. Here, the higher ADP-stimulated respiration and tightly coupled energy transfers within the oxidative muscle fibers might have enabled the higher respiratory oxygen expenditure and slower glycolysis activation.

\section{Limitations of the study}

In addition to the above topics, two further aspects must be accounted for in the interpretation of the results. Firstly, we must consider the different leverage effect of the RR and $\Delta \mathrm{IL}-6_{\text {IRB }}$ on $T_{\text {I_IRB }}$ modulation before in comparison to after thermal interventions. It may be taken as a further indirect proof of impact of thermal interventions on energy storage of respiratory muscles..$^{30}$ In addition, the above mentioned $T_{\text {I_IRB }}$ modulation might reflect changes in readiness for task performance fostered by both thermal treatments ${ }^{31,32}$ Consequently, the lack of a placebo may be viewed as a weakness of the study. However, it was virtually impossible to simulate sham mud pack applications.

While we acknowledge that the specific therapeutic effect of comparator treatment model would have limited the observed benefits of the treatment, we cannot exclude that a placebo intervention would have had in turn a certain therapeutic effect associated with the relationship between participants and the thermal care entourage. ${ }^{33}$ Second, we cannot completely rule out the possibility of unequal provision of care according to the treatment/comparator administered because the comparator treatment consisted of an unsupervised intervention, while treatment was administered by trained therapists. ${ }^{34}$ Nonetheless, supervision of each single thermal intervention by the thermal physician ensured that all the patients were well supported according to their needs.

Bias arising from different expertise among care providers is excluded due to their long working experience at highvolume thermal hotels participating in the study. ${ }^{35}$ Further, we did not cluster the patients according to thermal therapists they were treated by. However, our outcomes were objective quantitative and prespecified measurements.

\section{Adherence and safety}

The findings that neither treatment nor comparator modify at a significant extent the baseline values of cytokine IL-6, CRP, and ACTH either before or after thermal interventions stand for the safety of thermal interventions themselves.

Nonserious adverse events occurred in two patients allocated to the MBT group. In one case, it resulted in lower adherence to treatment, and in the other, it occurred after completion of the 12 treatment sessions. We can neither exclude nor prove a direct dependence of these events on medicinal clays application.

According to patients' logs of adherence to thermal treatments, we documented a higher adherence to the scheduled sessions of spa than to mud packs, which may suggest, but not prove that a higher volume of treatment was administered at the MBT groups than at LTA group.

\section{Conclusion}

At present, none of the available HT modalities are used as a systemic treatment option for patients suffering from COPD. Implementation of MBT in this disease condition should be not intended as a replacement of other traditional pharmacologic or rehabilitative treatments, but taken into account as an option to help COPD patients staving off the vicious circle of deconditioning.

MBT represents $\sim 40 \%$ of all HT treatments used worldwide. ${ }^{36}$ Implementation of MBT treatment model in COPD population (GOLD stage I-III) as a stimulator of endurance capacity of respiratory muscle is in line with the global strategy foreseen by the Hydroglobe project. ${ }^{36}$ We acknowledge that lack of a healthy control group limits the external validity of our results, and further studies with higher numbers of patients and healthy controls are needed to confirm them. Similarly, another obvious limitation of our results is that our conclusions specifically apply to medicinal clays of BIOCE field, whose availability is limited to the spa resorts of a specific geographical area in Italy. 
The issue of comparing the properties of medicinal clays from different sites within and between the countries is crucial. In addition, medicinal clays should also be available to health care rehabilitation centers and not to only high-volume centers with highly trained therapists.

\section{Acknowledgments}

The authors acknowledge Dr Alberto Lalli, President of OMTH, and Dr Maria Teresa Larovere, Scientific Director at our Institution, for their strong support to the project, Davide Barberio, Ph.D., and Nadia Dani, Ph.D., Bioclarma - Research and Molecular Diagnostics, for their technical help. Thanks to all the patients participating in the study. Study registration with ClinicalTrials.gov: No NCT01253941.

\section{Authors' contributions}

All authors made substantial contributions to conception and design, acquisition of data, or analysis and interpretation of data; took part in either drafting the article or revising it critically for important intellectual content; gave final approval of the version to be published; and agree to be accountable for all aspects of the work in ensuring the accuracy and integrity of any part of the work.

\section{Disclosure}

FC is paid for his directorship from Center of Thermal Studies Pietro D'Abano. Center of Thermal Studies Pietro D'Abano is co-founder in Fondazione per la Ricerca Scientifica Termale. SB was the winner of the call for tenders of 2010 grant of Fondazione per la Ricerca Scientifica Termale. The study project was supported by Fondazione S Maugeri, and it was co-founded at $56 \%$ by Fondazione per la Ricerca Scientifica Termale. The authors SB, GDP, CB, RM, ED, AR, EP, EB, PC, SM, and CF have no conflicts of interest to declare in this work.

\section{References}

1. Bellometti S, Galzigna L, Richelmi P, Gregotti C, Bertè F. Both serum receptors of tumor necrosis factor are influenced by mud pack treatment in osteoarthritis patients. Int J Tissue React. 2002;24(2):57-64.

2. Bellometti S, Richelmi P, Tassoni T, Bertè F. Production of matrix metalloproteinase and their inhibitors in osteoarthritic patients undergoing mud bath therapy. Int J Clin Pharmacol Res. 2005;25(2):77-94.

3. Bender T, Bariska J, Vághy R, Gomez R, Kovács I. Effect of balneotherapy on the antioxidant system - a controlled pilot trial. Arch Med Res. 2007;38(1):86-89.

4. Costantino M, Giuberti G, Caraglia M, et al. Possible anti-oxidant role of SPA therapy with chlorine-sulphur-bicarbonate mineral water. Amino Acids. 2009;36(2):161-165.

5. Pellegrini M, Fanin D, Nowicki Y, et al. Effect of inhalation of thermal water on airway inflammation in chronic obstructive pulmonary disease. Respir Med. 2005;99(6):748-754.
6. Guarnieri G, Ferrazzoni S, Scarpa MC, Lalli A, Maestrelli P. Effects of inhalation of thermal water on exhaled breath condensate. Respiration. 2010;79(3):216-221.

7. Bishop D. Warm up I. Potential mechanisms and the effects of passive warm up on exercise performance. Sports Med. 2003;33(6): 439-454.

8. Galzaniga L, Moretto C, Lalli A. Physical and biochemical changes of thermal mud after maturation. Biomed Pharmacother. 1996;50(6-7): 306-308.

9. Vernooy JH, Küçükaycan M, Jacobs JA, et al. Local and systemic inflammation in patients with chronic obstructive pulmonary disease: soluble tumor necrosis factor receptors are increased in sputum. Am J Respir Crit Care Med. 2002;166(9):1218-1224.

10. Godoy I, Campana AO, Geraldo RR, Padovani CR, Paiva SA. Cytokines and dietary energy restriction in stable chronic obstructive pulmonary disease patients. Eur Respir J. 2003;22(6):920-925.

11. Koechlin C, Couillard A, Cristol JP, et al. Does systemic inflammation trigger local exercise-induced oxidative stress in COPD? Eur Respir J. 2004;23(4):538-544.

12. Vassilakopoulos T, Zakynthinos S, Roussos C. Strenuous resistive breathing induces pro-inflammatory cytokines and stimulates the HPA axis in humans. Am J Physiol. 1999;277(4 pt 2):R1013-R1019. Erratum in: Am J Physiol. 1999;277(6 Pt 2):Preceding 1541.

13. Vassilakopoulos T, Hussain SN. Ventilatory muscle activation and inflammation: cytokines, reactive oxygen species, and nitric oxide. J Appl Physiol. 2007;102(4):1687-1695.

14. Vestbo J, Hurd SS, Agustí AG, et al. Global strategy for the diagnosis, management, and prevention of chronic obstructive pulmonary disease. Gold executive summary. Am J Respir Crit Care Med. 2013;187(4): 347-365.

15. Quanjer PH, Tammeling GJ, Cotes JE, et al. Standardized lung function testing. Eur Respir J. 1993;6(3):5-40.

16. Black LF, Hyatt RE. Maximal static respiratory pressures: normal value and its relationship to age and sex. Am Rev Respir Dis. 1969;99(5): 696-702.

17. General Guidelines for Methodologies on Research and Evaluation of Traditional Medicine Geneva WHO/EDM/TRM/2000.1, Page 9. WHO, Guidelines on Developing Consumer Information on Proper Use of Traditional, Complementary and Alternative Medicine. Geneva: WHO; 2004. Available from: http://apps.who.int/medicinedocs/en/d/ Js5525e/v

18. Fuster A, Sauleda J, Sala E, et al. Systemic inflammation after inspiratory loading in chronic obstructive pulmonary disease. Int $J$ Chron Obstruct Pulmon Dis. 2008;3(1):149-153.

19. Martyn JB, Moreno RH, Paré PD, Pardy RL. Measurement of inspiratory muscle performance with incremental threshold loading. Am Rev Respir Dis. 1987;135(4):919-923.

20. Iranmanesh A, Rochester DF, Liu J, Veldhuis JD. Impaired adrenergicand corticotrophic-axis outflow during exercise in chronic obstructive pulmonary disease. Metabolism. 2011;60(11):1521-1529.

21. Holloszy JO. Biochemical adaptation in muscles. Effects of exercise on mitochondrial oxygen uptake and respiratory enzyme activity in skeletal muscle. J Biol Chem. 1967;242(9):2278-2282.

22. Morgan TE, Cobb LA, Short FA, Ross R, Gunn DR. Effect of long term exercise on human muscle mitochondria. In: Pernow B, Saltin B, editors. Muscle Metabolism During Exercise. New York: Plenum; 1971: $87-95$.

23. Orozco-Levi M, Gea J, Lloreta JL, et al. Sub cellular adaptation of the human diaphragm in chronic obstructive pulmonary disease. Eur Respir J. 1999;13(2):371-378.

24. Ribera F, N'Guessan B, Zoll J, et al. Mitochondrial electron transport chain function is enhanced in inspiratory muscles of patients with chronic obstructive pulmonary disease. Am J Respir Crit Care Med. 2003; 167(6):873-879.

25. Zoll J, Sanchez H, N'Guessan B, et al. Physical activity changes the regulation of mitochondrial respiration in human skeletal muscle. J Physiol. 2002;543(pt-1):191-200. 
26. Brooks GA, Hittelman KJ, Faulkner JA, Beyer R. Temperature, skeletal muscle mitochondrial functions, and oxygen debt. Am J Physiol. 1971;220(4):1053-1059.

27. Power A, Pearson N, Pham T, Cheung C, Phillips A, Hickey A. Uncoupling of oxidative phosphorylation and ATP synthase reversal within the hyper-thermic heart. Physiol Rep. 2014;2(9):e12138.

28. Steensberg A, van Hall G, Osada T, Sacchetti M, Saltin B, Pedersen BK. Production of interleukin 6 in contracting human skeletal muscles can account for the exercise induced increase in plasma IL-6. JPhysiol. 2000; 29:237-242.

29. Pedersen BK, Steensberg A, Schjerling P. Muscle-derived interleukin-6: possible biological effects. J Physiol. 2001;536(pt 2):329-337.

30. Blank S, Chen V, Ianuzzo CD. Biochemical characteristics of mammalian diaphragms. Respir Physiol. 1988;74(1):115-125.

31. Raux M, Straus C, Redolfi S, et al. Electroencephalographic evidence for pre-motor cortex activation during inspiratory loading in humans. J Physiol. 2007;578(pt 2):569-578.

32. Paulus MP, Flagan T, Simmons AN, et al. Subjecting elite athletes to inspiratory breathing load reveals behavioral and neural signatures of optimal performers in extreme environments. PLoS One. 2012; 7(1):e29394.
33. Boutron I, Guittet L, Estellat C, Moher D, Hróbjartsson A, Ravaud P. Reporting methods of blinding in randomized trials assessing nonpharmacological treatments. PLoS Med. 2007;4(2):e61.

34. Boutron I, Tubach F, Giraudeau B, Ravaud P. Blinding was judged more difficult to achieve and maintain in non-pharmacologic than pharmacologic trials. J Clin Epidemiol. 2004;57(6):543-550.

35. Devereaux PJ, Bhandari M, Clarke M, et al. Need for expertise based randomised controlled trials. BMJ. 2005;330(7482):88.

36. FEMTEC FoRST. HydroGlobe-Definition of a Global Framework for Hydrotherapy (A FEMTEC-FoRST Joint Project with the Cooperation of ISMH and the Technical Support of WHO); 2013. Available from: http://www.ismh-direct.net/dokumentumok.aspx?Ord=1. Accessed September 17, 2013.

\section{Publish your work in this journal}

The International Journal of COPD is an international, peer-reviewed journal of therapeutics and pharmacology focusing on concise rapid reporting of clinical studies and reviews in COPD. Special focus is given to the pathophysiological processes underlying the disease, intervention programs, patient focused education, and self management protocols.

\section{Dovepress}

This journal is indexed on PubMed Central, MedLine and CAS. The manuscript management system is completely online and includes a very quick and fair peer-review system, which is all easy to use. Visit $\mathrm{http}: / /$ www.dovepress.com/testimonials.php to read real quotes from published authors. 